\title{
A Study on Impact of Pharmacist Interventions on Therapeutic Outcomes of Type II Diabetic Patients in a Tertiary Care Teaching Hospital
}

\author{
Voleti Vijaya Kumar ${ }^{1, *}$, Ankala Hemanth Reddy ${ }^{1}$, Jinkala Sudharshan', Gudemella Lokendranath ${ }^{2}$, RE \\ Ugandar ${ }^{1}$, Challa Madhusudhana Chetty ${ }^{1}$
}

${ }^{1}$ Department of Pharmacy Practice, Santhiram College of Pharmacy, Nandyal, Andhra Pradesh, INDIA.

${ }^{2}$ Department of General Medicine, Santhiram Medical College \& General Hospital, Nandyal, Andhra Pradesh, INDIA.

\begin{abstract}
Background: The management of type II diabetes mellitus is a complex, which requires continuous medical care by the health care professionals and good self-care efforts by patients. Pharmacist interventions programs delivered by the pharmacists are known to help the patients with diabetes benefited in achieving treatment goals, improving outcomes. Objectives: To study the impact of pharmacist interventions on therapeutic outcomes, determined by hemoglobin $\mathrm{A} 1 \mathrm{c}\left(\mathrm{HbA}_{1 \mathrm{c}}\right)$ and secondarily on blood glucose levels, blood pressure, medication adherence, self-care activities and health related quality of life. Materials and Methods: A Prospective randomized controlled study is conducted with 150 type II diabetic patients. Of those, 75 patients were in intervention group received the pharmacist interventions over a period of 4 months and 75 patients were in control group, whereas control group do not receive interventions. The primary outcome measure was change in $\mathrm{HbA}_{1 \mathrm{c}}$ and secondary outcomes were changes in fasting blood glucose, blood pressure, medication adherence, self-care activities and health related quality of life. Results: A population of 150 patients completed the study. The intervention patients exhibited a significant reduction in $\mathrm{HbA}_{1 \mathrm{c}}$ values than the control group, the intervention group showed a greater reduction in the fasting blood glucose and blood pressure levels between baseline and end of the 4 months than the control group. Improvements were observed in Quality of life, self-reported medication adherence, self-care activities in the intervention group. Conclusion: A pharmacist interventions program resulted in better glycemic control, quality of life, medication adherence and self-care of type II diabetic patients over a 4-month period.
\end{abstract}

Key words: Type II Diabetes, Pharmacist interventions, $\mathrm{HbA}_{1 \mathrm{c}}$, Quality of life, Adherence.

\section{INTRODUCTION}

Diabetes mellitus is a metabolic disease that directly affects well-being and poses a high morbidity risk. The long-term vascular complications associated with type II diabetes accounts for the majority belonging to morbidity and mortality in patients. ${ }^{1}$ Several studies shown that lowering hemoglobin A1c is associated with reduced onset or progression of micro vascular complications. ${ }^{2}$ Treatment strategies applied for type II diabetes are complex, requiring ongoing medical care, continuing patient education and support to prohibit acute complications and minimize the risk of chronic complications. ${ }^{3}$

Pharmacists can play crucial role in diabetes treatment by helping patients improve their chances of reaching the curative and lifestyle goals. As experts in drug selection, identification of drug related problems and patient education pharmacists can be excellent additions to multidisciplinary health care team, contributing to better care for patients. ${ }^{4}$ They can help in patients individually or with other health professionals in designing, implementing and monitoring therapeutic plans to achieve good disease outcomes by pharmacist interventions. ${ }^{5}$

Pharmaceutical care programs developed and executed by pharmacists have been found effective in improving the quality of care for patients suffering with various diseases such as hypertension, asthma, dyslipidemia, heart failure and tuberculosis. Pharmacist-
DOI: 10.5530/ijopp.13.3.42

Address for correspondence: Mr. Voleti Vljaya Kumar (M. Pharm., (Ph.D)

Associate Professor, Department of Pharmacy Practice, Santhiram College of pharmacy, Nandyal518112, Andhra Pradesh, INDIA. Phone no: +919885583630 Email Id: vijay66vvk@gmail.com

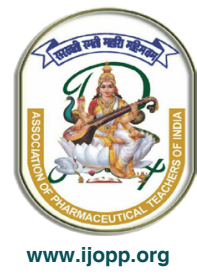


led care programs improve glycemic control and various outcomes such as weight reduction, blood pressure and the quality of life in patients with diabetes. ${ }^{6}$ Some studies have demonstrated the clinical and economic benefits of various clinical pharmacy services in hospital settings. ${ }^{7,8}$

Medication regimens of type II diabetic patients are often complex and appropriate use of medications is important for the success of diabetes care which is associated with great level of self-care behavior and self-management. ${ }^{9}$ Poor adherence to diabetes treatment is common among the patients and it can cause severe complications, increased mortality. ${ }^{10}$ Responsibilities of pharmacist include the optimization of medical treatment and adherence to medication. Pharmacist interventions have the potential for improving the adherence to medications for type II diabetes in such different settings as face-toface meetings, group activity and telephone follow up.

The goal of this study to assess the impact of pharmacist interventions in a tertiary care teaching hospital on the clinical outcomes of glycemic control which is determined primarily by $\mathrm{HbA}_{1 c}$. Secondary outcomes include effect on blood pressure, Quality of life, medication adherence and self-care activities for type II diabetic patients over a 4-month period.

\section{MATERIALS AND METHODS}

Study Design: This study was a prospective randomized controlled study with 150 patients at a Santhiram Medical College and General Hospital, Nandyal. The patients were divided into two groups: 75 were in the intervention group and 75 were in the control group. The patients were recruited from the general medicine wards and from endocrinology and medical outpatient clinics.

Study Site: This study was conducted in Santhiram Medical College and General Hospital, Nandyal.

Study Period: The present study was carried out for a period of seven months from July-2019 to December 2019.

Institutional Ethics Committee (IEC): After the approval of Institutional Human Ethics Committee, at Santhiram Medical College and General Hospital, Nandyal this study was initiated.

\section{Sample size}

A sample size calculation, based on the published data on the variability (standard deviation $[\mathrm{SD}]=2.1 \%$ ) of $\mathrm{HbA}_{1 \mathrm{c}}$ in type 2 diabetic patients, indicated that to detect absolute difference of minimum of $1 \% \mathrm{HbA}_{1 \mathrm{c}}$, with $\alpha=0.05$ and a power of $80 \%$ and a sample size of 64 patients was needed in both intervention and control groups. However, taking into consideration that patients could miss follow up (15\%), it was estimated that 74 patients would be requires for each group.

\section{Study subjects Inclusion criteria}

Patients with the type II diabetes mellitus confirmed diagnosis by hospital consultant, receiving oral hypoglycemic therapy, patients able to visit hospital regularly and patient provided written consent to their participation for patient to entering into the study.

\section{Exclusion criteria}

Patients were excluded from the study if they are pregnant woman, children and if they had uncontrolled psychiatric disorder who are suffering with diabetes.

After recruitment patients were randomly assigned for one of the two groups, intervention group and control group and they were identified by their registration number.

\section{Baseline measures and assessments}

After recruitment every patient was interviewed directly for approximately $15 \mathrm{~min}$ by the research pharmacist and a detailed chart review undertaken to obtain specific details on demographics, family history of diabetes, medications being used, diabetes symptoms, frequency of daily blood glucose monitoring, diabetes and medication knowledge, adherence to medication and life style advise and to record the $\mathrm{HbA}_{1 \mathrm{c}}$, fasting blood glucose, post prandial blood glucose, systolic and the diastolic blood pressure. Patients were also asked to self-complete the questionnaires on health-related quality of life [short form 36], adherence scale [Morisky green Levine test] and self-care activities [SDSCA]. If they are incapableto fill themselves the research pharmacist ask the questionnaire and filled it in front of patients.

\section{Description of interventions}

Patients who are randomized all over to the intervention group were educated by research pharmacist on their illness and their medication including the risk of diabetes complications, proper dosage, time and route of administration, side effects and storage of medications, importance of self-monitoring of glucose, a healthy diet, physical exercise and smoking cessation, healthy life style and reducing of type II diabetes signs and symptoms through self-monitoring. In addition to this behavioral modification aspects for patients were physical exercise this involved by the initiation of an 
exercise plan that could be habituated into the patient's daily schedule after taking into consideration of their physical fitness, e.g. 1-hr walk daily; diet include dietary plan that influences the good blood glucose control; medication adherence i.e., patients were offered education and practical help to encourage them for administering of medicines prescribed to them by the physician; and smoking cessation patients were advised to stop smoking. The patients who are randomized to the control group received their normal care but did not receive the clinical pharmacy service, i.e. did not receive pharmacist input into treatment plans or patient education.

\section{Short form 36}

The short form 36 is a health survey which used to measure the health-related quality of life in patients with disorders. It is useful in evaluating individual patient's health status, monitoring and comparing the disease burden on quality of life. ${ }^{11}$

The short form 36 consists of nine scaled scores which are weighted sums of the questions in their class. Each scale is directly transformed into 0-100 scale. The lower score indicates more disability. The higher score indicates the less disability.

\section{The nine sections are}

1. Physical functioning

2. Social functioning

3. General health

4. Emotional well being

5. Physical role functioning

6. Emotional role functioning

7. Energy/fatigue

8. Pain

9. Health change

\section{SDSCA Questionnaire}

The SDSCA questionnaire is a well-documented, validated tool that measures the self-care behavior of the patients. It has five sections each section is answered and scored separately by recalling their self-care behaviors during the previous seven days. ${ }^{12}$

1. Diet (4 questions), for example "How many of the last seven days have you followed a healthy eating plan?

2. Exercise (2 questions), for example "During how many of the last seven days did you participate in at least thirty min of physical activity?

3. Foot care (2 questions), for example "During how many of the last seven days did you check your feet?

4. Smoking (2 questions), for example "Have you smoked a cigarette during past seven days?

5. Medication (1 question) "Have you forget the administration of medication in past seven days?

\section{Adherence}

Medication adherence was assessed using the moriskygreen test at baseline and end of the third month. This test consists of 4 questions.

1. Do you ever forgotten to take medications?

2. Are you careless at times about taking medication?

3. When you feel better do you stop taking medications?

4. When you feel worse do you stop taking medications?

Patients were considered adherent when they answered "no" to all questions. If a patient answered "yes" to any question, the patient was considered as non-adherent. ${ }^{12}$

\section{Outcome measures}

Both groups of patients were asked to come back to the hospital clinic for every month followed in the hospital to allow the follow-up assessments. All the patients of intervention group and control group were assessed as per their initial baseline assessment at their scheduled clinic visits by the research pharmacist. Where a standard protocol for administration of questionnaire were used for measurement of quality of life, adherence and selfcare activities to reduce the potential bias. The latter outcome measures were only assessed at baseline and 4 months.

\section{Statistical analysis}

The results were analyzed and tabulated statistically by using SPSS software version 22.0. Fishers test is used to compare the categorical variables. Two-sample comparisons were made using Student's t-tests and a value of $p \leq 0.01$ is taken as statistical significance.

\section{RESULTS}

During the study period, 150 eligible patients were recruited. Out of 75 patients were in intervention group and 75 patients were in control group completed the study. Patient characteristics were explained in Table 1. 
Table 1: Patient demographics and clinical

characteristics at baseline.

\begin{tabular}{|c|c|c|c|}
\hline $\begin{array}{l}\text { Demographic } \\
\text { and Clinical } \\
\text { characteristics }\end{array}$ & $\begin{array}{l}\text { Intervention } \\
\text { group } \\
(n=75)\end{array}$ & $\begin{array}{c}\text { Control group } \\
(n=75)\end{array}$ & $\begin{array}{c}P \\
\text { value }\end{array}$ \\
\hline $\begin{array}{l}\text { Age in years, } \\
\text { mean } \pm S D\end{array}$ & $56.6 \pm 9.34$ & $58.8 \pm 9.6$ & 0.785 \\
\hline \multicolumn{4}{|c|}{ Gender, n (\%) } \\
\hline Male & $40(53.3)$ & $48(64)$ & \multirow{2}{*}{0.14} \\
\hline Female & $35(46.6)$ & $27(36)$ & \\
\hline \multicolumn{4}{|c|}{ Marital Status, n (\%) } \\
\hline Married & $73(97.3)$ & $73(97.3)$ & \multirow{2}{*}{0.5} \\
\hline Single, divorced & $2(2.7)$ & $2(2.7)$ & \\
\hline \multicolumn{4}{|c|}{ Education: } \\
\hline Illiterate & $42(56)$ & $47(55)$ & \multirow{2}{*}{0.28} \\
\hline Literate & $33(44)$ & $20(38)$ & \\
\hline \multicolumn{4}{|c|}{ Working status, n (\%) } \\
\hline Domestic & $4(5.33)$ & $1(1.3)$ & \multirow{4}{*}{0.31} \\
\hline Employee & $6(8)$ & $1(1.3)$ & \\
\hline Agriculture & $40(53.3)$ & $49(65.3)$ & \\
\hline Sedentary & $25(33.3)$ & $24(32)$ & \\
\hline \multicolumn{4}{|c|}{ Diet, n (\%) } \\
\hline Veg & $7(9.3)$ & $5(6.6)$ & \multirow[b]{2}{*}{0.47} \\
\hline $\begin{array}{l}\text { Mixed diet (non } \\
\text { veg) }\end{array}$ & $68(90.7)$ & $70(93.3)$ & \\
\hline \multicolumn{4}{|c|}{ Duration of diabetes in years, $n(\%)$} \\
\hline De novo & $11(14.6)$ & $5(6.6)$ & \multirow{4}{*}{0.35} \\
\hline $1-10$ & $47(62.6)$ & 55 (73.3) & \\
\hline $11-20$ & $15(20)$ & $15(20)$ & \\
\hline $21-30$ & $2(2.6)$ & $0(0)$ & \\
\hline \multicolumn{4}{|c|}{ Habits, n (\%) } \\
\hline Smokers & $12(16)$ & $21(28)$ & \multirow{2}{*}{0.36} \\
\hline Non smokers & $63(84)$ & $54(72)$ & \\
\hline Alcoholics & $14(18.6)$ & $20(26.6)$ & \multirow{2}{*}{0.4} \\
\hline Non alcoholics & $61(81.4)$ & $55(73.4)$ & \\
\hline \multicolumn{4}{|c|}{ Anti-diabetic medications, $\mathrm{n}(\%)$} \\
\hline Metformin & $60(80)$ & $62(82.6)$ & \\
\hline Sulphonyl urea's & $48(64)$ & $48(64)$ & \\
\hline Insulin & $30(40)$ & $30(40)$ & 0.44 \\
\hline Others & $5(6.6)$ & $4(5.3)$ & \\
\hline Anti-hypertensives & $18(24)$ & $14(18.6)$ & \\
\hline
\end{tabular}

$\mathrm{SD}=$ Standard Deviation

Statistical analyses indicate that the groups were well matched $(p>0.05)$ in all patient characteristics.

\section{$\mathrm{HbA}_{1 \mathrm{c}}$, FBS and PPBS}

The intervention group patients achieved a significant reduction in $\mathrm{HbA}_{1 \mathrm{c}}$ values $(P<0.001)$ than the usual care patients (mean difference- $1.18 \%$ vs. $-0.51 \%$ ) at the end of four-month study period (Table 2). The intervention group patients $(P<0.001)$ show a greater reduction of
FBS values (mean difference $-81 \mathrm{mg} / \mathrm{dl}$ vs. $-44 \mathrm{mg} / \mathrm{dl}$ ) and PPBS values (mean difference $-127 \mathrm{mg} / \mathrm{dl}$ vs. $-81 \mathrm{mg} / \mathrm{dl}$ ) than control group patients $(P=0.1)$ at the end of fourmonth study period.

\section{Systolic and Diastolic blood pressure}

Comparing the intervention group with control group there were significant decreases in systolic blood pressure $(p<0.001)$ of intervention group than control group systolic blood pressure $(P=0.80)$ and the diastolic blood pressure of both groups have a similar reduction $(p<0.01)$ over the 4-month study period (Table 2).

\section{Health related Quality of life (SF36 questionnaire)}

In the SF36 some domains almost have the same score at baseline but after four-month study period the intervention group patients have the higher domain scores $(P<0.001)$. This shows intervention group patient's quality of life was improved better than control group over the 4-month study period (Table 3).

\section{Self-care activities (SDSCA score)}

Patients in intervention group achieved significant improvements in their total diet score $(p<0.01)$, total foot care score $(p<0.01)$, total medication score $(p<0.01)$ versus usual care patients (Table 4$)$. Patients in the control group didn't achieve any significant improvements in the any of above domains except for the total exercise score of both the groups were same at the end of 4-month study period.

\section{Adherence}

According to the Morisky Green Levine test at baseline $46.6 \%$ of intervention group and $34.6 \%$ of control group patients were adherents (Table 5). At the end of study $86.6 \%$ of intervention group patients and $49.3 \%$ of control group patients were adherent. During study period intervention group showed a significant increase $(p<.001)$ in pharmacotherapy adherence whereas the control group showed slighter changes compared with baseline values $(p=0.13)$.

\section{DISCUSSION}

The present study was designed to measure the impact of pharmacist interventions on the clinical outcomes of the patients with type II diabetes mellitus. During study period 150 eligible patients were identified. In the 150 patients 75 patients were in intervention group and 75 patients were in control group. The baseline clinical parameters of the patients were collected from the first visit of the patients to the hospital.

Indian Journal of Pharmacy Practice, Vol 13, Issue 3, Jul-Sep, 2020 
We observed a significant reduction in mean $\mathrm{HbA}_{1 \mathrm{c}}$ values from $8.34 \%$ to $7.16 \%(\phi<0.001)$. Pharmacist interventions in other studies carried out in different settings also showed reduction in $\mathrm{HbA}_{1 \mathrm{c}}$ levels. A recent study by Korcegez et al. (2017) showed reduction in $\mathrm{HbA}_{1 \mathrm{c}}$ values $8.29 \%$ to $7.55 \%$ in northern cyphrus. ${ }^{14}$ According to the United Kingdom Prospective diabetes study each $1 \%$ of reduction in the $\mathrm{HbA}_{1 \mathrm{c}}$ levels reduce the risk of death related to diabetes by $21 \%$ and micro vascular complications by $37 \%$. The improvements in $\mathrm{HbA}_{1 \mathrm{c}}$ in the present study were probably due to improved medication adherence to the prescribed medications and lifestyle modifications. The reduction in the $\mathrm{HbA}_{1 \mathrm{c}}$ levels $(1.6 \%)$ in this study is beneficial because it suggests that a clinical pharmacist can significantly contribute to improved $\mathrm{HbA}_{1 \mathrm{c}}$ values, which can reduce clinical complications.

A positive impact on blood glucose levels were seen in this study. The fasting blood glucose in the patients of intervention group showed a significant reduction when compared to control group $(-81 \mathrm{mg} / \mathrm{dl}$ vs. $-44 \mathrm{mg} / \mathrm{dl})$ the difference was significant $(p<0.001)$. A study conducted

Table 2: Changes in therapeutic outcomes between Groups from baseline to end line.

\begin{tabular}{|c|c|c|c|c|c|c|c|c|}
\hline \multirow{2}{*}{ Clinical parameter } & \multicolumn{4}{|c|}{ Intervention group } & \multicolumn{4}{|c|}{ Control group } \\
\hline & $\begin{array}{l}\text { Baseline } \\
\text { mean士SD }\end{array}$ & $\begin{array}{l}\text { End line } \\
\text { Mean士SD }\end{array}$ & $\begin{array}{c}\text { Mean } \\
\text { difference }\end{array}$ & $P$ value & $\begin{array}{l}\text { Baseline } \\
\text { mean } \pm S D\end{array}$ & $\begin{array}{l}\text { End line } \\
\text { Mean士SD }\end{array}$ & $\begin{array}{c}\text { Mean } \\
\text { difference }\end{array}$ & $P$ value \\
\hline $\mathrm{HbA}_{1 \mathrm{c}} \%$ & $8.34 \pm 2.4$ & $7.16 \pm 1.57$ & -1.18 & $<0.001$ & $7.18 \pm 1.54$ & $7.12 \pm 1.35$ & -0.51 & 0.3 \\
\hline $\begin{array}{l}\text { Fasting blood } \\
\text { glucose (mg/dl) }\end{array}$ & $191.4 \pm 63.8$ & $110.4 \pm 22.65$ & -81 & $<0.001$ & $178.9 \pm 53.8$ & $134.1 \pm 40.3$ & -44 & 0.1 \\
\hline $\begin{array}{l}\text { Post prandial blood } \\
\text { glucose }(\mathrm{mg} / \mathrm{dl})\end{array}$ & $279.9 \pm 93.8$ & $152.6 \pm 28.9$ & -127 & $<0.001$ & $274.5 \pm 84.5$ & $193.1 \pm 53.5$ & -81 & 0.01 \\
\hline $\begin{array}{l}\text { Systolic blood } \\
\text { pressure }(\mathrm{mmHg})\end{array}$ & $133.1 \pm 21.3$ & $121.2 \pm 3.6$ & -12 & $<0.001$ & $129.6 \pm 14.3$ & $123.6 \pm 14.8$ & -6 & 0.5 \\
\hline $\begin{array}{l}\text { Diastolic blood } \\
\text { pressure }(\mathrm{mmHg})\end{array}$ & $84.9 \pm 14.9$ & $80 \pm 0$ & -2 & $<0.001$ & $83.2 \pm 5.6$ & $81.2 \pm 3.2$ & -0.2 & 0.02 \\
\hline
\end{tabular}

Table 3: Summary of Short Form 36 data.

\begin{tabular}{|c|c|c|c|c|c|c|}
\hline \multirow[b]{2}{*}{ Domain } & \multicolumn{3}{|c|}{ Intervention group } & \multicolumn{3}{|c|}{ Control group } \\
\hline & $\begin{array}{c}\text { Baseline mean } \\
\pm S D\end{array}$ & $\begin{array}{c}\text { End of } \\
\text { studymean } \pm S D\end{array}$ & $P$ value & $\begin{array}{c}\text { Baseline mean } \\
\pm S D\end{array}$ & $\begin{array}{l}\text { End of } \\
\text { study } \pm S D\end{array}$ & $P$ value \\
\hline Physical functioning & $66.8 \pm 11.28$ & $77 \pm 11.08$ & 0.08 & $59 \pm 11.24$ & $62.2 \pm 8.97$ & 0.9 \\
\hline Social functioning & $76.5 \pm 10.67$ & $81.09 \pm 10.15$ & 0.6 & $73.1 \pm 9.07$ & $75.3 \pm 7.47$ & 0.92 \\
\hline General health & $77 \pm 10.3$ & $86.1 \pm 10.52$ & 0.08 & $72 \pm 10.29$ & $75.1 \pm 9.47$ & 0.46 \\
\hline Emotional well being & $73 \pm 10.09$ & $82 \pm 9.27$ & 0.46 & $68.3 \pm 9.03$ & $69.9 \pm 9.47$ & 0.68 \\
\hline Role-physical & $55.4 \pm 22.68$ & $64.8 \pm 19.65$ & 0.21 & $44 \pm 19.2$ & $50 \pm 15.52$ & 0.6 \\
\hline Role-emotional & $87.0 \pm 21.24$ & $93.7 \pm 14.17$ & 0.0001 & $89.3 \pm 18.3$ & $91.1 \pm 17.58$ & 0.7 \\
\hline Energy/Fatigue & $74.8 \pm 9.82$ & $81.5 \pm 8.46$ & 0.02 & $69.5 \pm 8.1$ & $73.4 \pm 8.24$ & 0.88 \\
\hline Pain & $61.2 \pm 18.31$ & $74.2 \pm 14.95$ & 0.08 & $55.6 \pm 14.8$ & $60.9 \pm 13.54$ & 0.42 \\
\hline Health change & $45.3 \pm 20.83$ & $59.6 \pm 19.66$ & 0.0001 & $42.2 \pm 19.0$ & $51.3 \pm 15.34$ & 0.06 \\
\hline
\end{tabular}

Table 4: Change in self-Care activity scores.

\begin{tabular}{|c|c|c|c|c|c|c|}
\hline \multirow[b]{2}{*}{ Self-care Activities } & \multicolumn{3}{|c|}{ Intervention group } & \multicolumn{3}{|c|}{ Control group } \\
\hline & $\begin{array}{c}\text { Baseline mean } \\
\pm S D\end{array}$ & $\begin{array}{c}\text { End of study } \\
\text { mean } \pm S D\end{array}$ & $P$ value & $\begin{array}{c}\text { Baseline mean } \\
\pm S D\end{array}$ & $\begin{array}{c}\text { End of study } \\
\text { mean } \pm S D\end{array}$ & $P$ value \\
\hline Total diet score & $3.32 \pm 0.67$ & $4.40 \pm 0.49$ & 0.006 & $3.12 \pm 0.53$ & $3.39 \pm 0.45$ & 0.16 \\
\hline Total exercise score & $1.99 \pm 1.46$ & $3.64 \pm 1.3$ & 0.52 & $1.43 \pm 0.79$ & $2.08 \pm 0.77$ & 0.82 \\
\hline Total foot care score & $1.44 \pm 1.39$ & $2.92 \pm 1.09$ & 0.005 & $1 \pm 0.63$ & $1.9 \pm 0.77$ & 0.08 \\
\hline Smokers (n) & 12 & 8 & 0.88 & 21 & 19 & 0.58 \\
\hline $\begin{array}{l}\text { Total medication } \\
\text { score }\end{array}$ & $5.4 \pm 1.41$ & $6.88 \pm 0.4$ & 0.001 & $5.32 \pm 1.31$ & $5.88 \pm 1.09$ & 0.04 \\
\hline
\end{tabular}




\begin{tabular}{|c|c|c|c|c|c|c|c|c|c|c|}
\hline \multirow[b]{2}{*}{$\begin{array}{l}\text { Adherence } \\
\text { assessment }\end{array}$} & \multicolumn{5}{|c|}{ Intervention group } & \multicolumn{5}{|c|}{ Control group } \\
\hline & Baseline & $\%$ & $\begin{array}{c}\text { End } \\
\text { of } \\
\text { study }\end{array}$ & $\%$ & $\begin{array}{c}P \\
\text { value }\end{array}$ & Baseline & $\%$ & $\begin{array}{l}\text { End } \\
\text { of } \\
\text { study }\end{array}$ & $\%$ & $\begin{array}{c}P \\
\text { value }\end{array}$ \\
\hline Adherent & 30 & 46.6 & 65 & 86.6 & \multirow{2}{*}{0.001} & 26 & 34.6 & 37 & 49.3 & \multirow{2}{*}{0.13} \\
\hline Non-Adherent & 45 & 66.4 & 10 & 13.3 & & 49 & 65.3 & 38 & 50.6 & \\
\hline
\end{tabular}

by a Mehuys et al. (2011), the intervention group (-14.1 $\mathrm{mg} / \mathrm{dl})$ and control group $(-8.1 \mathrm{mg} / \mathrm{dl})$ showed a reductions in the fasting blood glucose between baseline and end of the study, but the difference between then groups was not significant in that study. ${ }^{15}$ Mourao et al. (2013) study found a significant $21.4 \mathrm{mg} / \mathrm{dl}$ decrease in intervention group patients than control group patients. ${ }^{16}$

In our study comparing the intervention group with control group there were significant decreasingof systolic blood pressure $(p<0.001)$ of intervention group than control group systolic blood pressure $(P=0.80)$ and the diastolic blood pressure of both groups have a similar reduction $(P<0.01)$. In the present research an important finding was that more patients in intervention group $(68.1 \%)$ than in control group $(47.6 \%)$ achieved the target ADA blood pressure $(<140 / 90 \mathrm{mmHg})$. These results were an improvement on those reported by Jarab et al. (2012) reported small but significant improvements in systolic blood pressure levels $(P=0.035)$ and diastolic blood pressure levels $(P=0.026)$ over a 6 -month study. ${ }^{8}$

The improvement in health-related quality of life is increased due to contact of diabetic patients with the clinical pharmacist, associated with increased adherence and life style modifications. The results show the summary of SF 36 data between intervention group and control group from baseline to end of study. In the SF36 some domains almost have the same score at baseline but after 4-month study period the intervention group patients have the higher domain scores than the control group scores. This indicates intervention group patient's quality of life was improved better than the control group. The results of the present study indicate that pharmacist interventions can have a positive impact on the quality of life in patients of type I diabetes.

Our results, consistent with the earlier studies, show that pharmacist interventions can improve medication adherence and self-care activities. During study period the meetings with the pharmacist led to the development of patient-pharmacist professional relationship which may have increased the confidence of patients towards improved medication adherence and self-care activities.
Poor adherence to diabetes treatment is common among patients which may cause severe health complications. In this study according to the Morisky Green Levine test at baseline $46.6 \%$ of intervention group and 34.6\% of control group patients were adherent. At the end of study $86.6 \%$ of intervention group patients and $49.3 \%$ of control group patients were adherent. During study period intervention group showed a significant increase $(p<.001)$ in pharmacotherapy adherence at end of the study when compared to baseline. Whereas the control group showed slighter changes at the end of the study when compared with baseline values $(p=0.13)$.In the self-care activities patients in intervention group achieved significant improvements in their total diet score $(p<0.01)$, total foot care score $(p<0.01)$, total medication score $(p<0.01)$ versus usual care patients. Patients in control group did not achieve significant improvements in the any of above domains except for the total exercise score of both intervention group and control group were same. A recent study by Korcegez et al. (2017) showed no significant improvement in the exercise, smoking behaviour and foot care domains. ${ }^{17}$ The significant improvements in self-care activities in our study may be due to intense education provided by the pharmacist about life style modifications and non-pharmacological treatment and the availability of a pamphlet to the patients in intervention group.

\section{CONCLUSION}

The main finding of this study revealed that the pharmacist interventions have a positive effect on glycemic control as well as medication adherence. The pharmacist interventions can provide a care to the patients with type II diabetes by reducing $\mathrm{HbA}_{1 \mathrm{c}}$, FBS, PPBS, Blood pressure, improves the quality of life and self-care activities. In this study a pharmacist who was a qualified educator used his expertise to help the patients by providing the knowledge about disease management, encouraging them to reach their therapeutic outcomes and supporting them in adherence of the medications. The results of this study showed the therapeutic beneficiary of the many people with type II diabetes mellitus. 


\section{ACKNOWLEDGEMENT}

It is our immense pleasure to express our heartfelt gratitude and sincere thanks to Dr. G. Lokendranath M.D. (General Medicine), Professor, Department of General Medicine, SRGH, Nandyal for his supervision, guidance and support during the study.

We take this opportunity to acknowledge the management, principal, faculty and non-teaching staff of Santhiram College of Pharmacy, Nandyal for providing necessary facilities and timely help to complete our work.

\section{CONFLICT OF INTEREST}

The author(s) declared no potential conflicts of interests with respect to the research, authorship and/ or publication of this article.

\section{SUMMARY}

- The pharmacist interventions have a positive impact on therapeutic outcomes in type II diabetic patients.

- $\mathrm{HbA}_{1 \mathrm{c}}$ and blood glucose levels were well controlled in the type II diabetic patients with the pharmacist interventions.

- The pharmacist interventions will improve the Quality of life and medication adherence in the type II diabetic patients.

\section{REFERENCES}

1. Stratton IM, Adler AI, Neil HA, Matthews DR, Manley SE, Cull CA, Hadden D, Turner RC, Holman RR. Association of glycaemia with macrovascular and microvascular complications of type 2 diabetes (UKPDS 35): prospective observational study. Bmj. 2000;321(7258):405-12.

2. Singh A, Donnino R, Weintraub H, Schwartzbard A. Effect of strict glycemic control in patients with diabetes mellitus on frequency of macrovascular events. The American journal of cardiology. 2013;112(7):1033-8.
3. American Diabetes Association. Standards of medical care in diabetes-2015 abridged for primary care providers. Clinical diabetes: a publication of the American Diabetes Association. 2015;33(2):97.

4. Wubben DP, Vivian EM. Effects of pharmacist outpatient interventions on adults with diabetes mellitus: a systematic review. Pharmacotherapy: The Journal of Human Pharmacology and Drug Therapy. 2008;28(4):421-36.

5. Helper CD, Strand LM. Opportunities and responsibilities in pharmaceutical care. Am J Hosp Pharm. 1990;47(3):533-43.

6. Machado M, Bajcar J, Guzzo GC, Einarson TR. Sensitivity of patient outcomes to pharmacist interventions. Part I: systematic review and meta-analysis in diabetes management. Annals of Pharmacotherapy. 2007;41(10):1569-82.

7. Forjuoh SN, Huber C, Bolin JN, Patil SP, Gupta M, Helduser JW, Holleman S, Ory MG. Provision of counseling on diabetes self-management: Are there any age disparities?. Patient education and counseling. 2011;85(2):133-9.

8. Borges AP, Guidoni CM, Ferreira LD, de Freitas O, Pereira LR. The pharmaceutical care of patients with type 2 diabetes mellitus. Pharmacy world and science. 2010 1;32(6):730-6.

9. Antoine SL, Pieper D, Mathes T, Eikermann M. Improving the adherence of type 2 diabetes mellitus patients with pharmacy care: a systematic review of randomized controlled trials. BMC endocrine disorders. 2014;14(1):53.

10. Ho PM, Rumsfeld JS, Masoudi FA, McClure DL, Plomondon ME, Steiner JF, Magid DJ. Effect of medication nonadherence on hospitalization and mortality among patients with diabetes mellitus. Archives of internal medicine. 2006;166(17):1836-41.

11. Al Mazroui NR, Kamal MM, Ghabash NM, Yacout TA, Kole PL, McElnay JC. Influence of pharmaceutical care on health outcomes in patients with Type 2 diabetes mellitus. British journal of clinical pharmacology. 2009;67(5):547-57.

12. Toobert DJ, Hampson SE, Glasgow RE. The summary of diabetes self-care activities measure: results from 7 studies and a revised scale. Diabetes care. 2000 1;23(7):943-50.

13. Morisky DE, Green LW, Levine DM. Concurrent and predictive validity of a selfreported measure of medication adherence. Medical care. 1986; 1:67-74.

14. Korcegez El, Sancar M, Demirkan K. Effect of a pharmacist-led program on improving outcomes in patients with type 2 diabetes mellitus from Northern Cyprus: a randomized controlled trial. Journal of managed care and specialty pharmacy. 2017;23(5):573-82.

15. Mehuys E, Van Bortel L, De Bolle L, Van Tongelen I, Annemans L, Remon JP, Giri M. Effectiveness of a community pharmacist intervention in diabetes care: a randomized controlled trial. Journal of clinical pharmacy and therapeutics. 2011;36(5):602-13.

16. Mourão AO, Ferreira WR, Martins MA, Reis AM, Carrillo MR, Guimarães AG, Ev LS. Pharmaceutical care program for type 2 diabetes patients in Brazil: a randomised controlled trial. International journal of clinical pharmacy. 2013 1;35(1):79-86.

17. Jarab AS, Alqudah SG, Mukattash TL, Shattat G, Al-Qirim T. Randomized controlled trial of clinical pharmacy management of patients with type 2 diabetes in an outpatient diabetes clinic in Jordan. Journal of Managed Care Pharmacy. 2012;18(7):516-26. 